Article

\title{
Sustainable Micro-Manufacturing of Micro-Components via Micro Electrical Discharge Machining
}

\author{
Francesco Modica, Valeria Marrocco, Giacomo Copani and Irene Fassi * \\ Institute of Industrial Technologies and Automation, National Research Council (ITIA-CNR), \\ Via Bassini 15, Milano 20133, Italy; E-Mails: francesco.modica@itia.cnr.it (F.M.); \\ valeria.marrocco@itia.cnr.it (V.M.); giacomo.copani@itia.cnr.it (G.C.) \\ * Author to whom correspondence should be addressed; E-Mail: irene.fassi@itia.cnr.it; \\ Tel.: +39-02-23699921; Fax: +39-02-23699925.
}

Received: 8 October 2011; in revised form: 28 November 2011 / Accepted: 1 December 2011 / Published: 13 December 2011

\begin{abstract}
Micro-manufacturing emerged in the last years as a new engineering area with the potential of increasing peoples' quality of life through the production of innovative micro-devices to be used, for example, in the biomedical, micro-electronics or telecommunication sectors. The possibility to decrease the energy consumption makes the micro-manufacturing extremely appealing in terms of environmental protection. However, despite this common belief that the micro-scale implies a higher sustainability compared to traditional manufacturing processes, recent research shows that some factors can make micro-manufacturing processes not as sustainable as expected. In particular, the use of rare raw materials and the need of higher purity of processes, to preserve product quality and manufacturing equipment, can be a source for additional environmental burden and process costs. Consequently, research is needed to optimize micro-manufacturing processes in order to guarantee the minimum consumption of raw materials, consumables and energy. In this paper, the experimental results obtained by the micro-electrical discharge machining (micro-EDM) of micro-channels made on $\mathrm{Ni}-\mathrm{Cr}-\mathrm{Mo}$ steel is reported. The aim of such investigation is to shed a light on the relation and dependence between the material removal process, identified in the evaluation of material removal rate (MRR) and tool wear ratio (TWR), and some of the most important technological parameters (i.e., open voltage, discharge current, pulse width and frequency), in order to experimentally quantify the material waste produced and optimize the technological process in order to decrease it.
\end{abstract}


Keywords: micro-manufacturing process; micro-electro-discharge machining

\section{Introduction}

In the last years, progress in disciplines such as biomedical engineering, electronics, telecommunications and advanced materials, required manufacturers to produce new components at micro level. Micro-manufacturing emerged as a new promising engineering area capable of enhancing people's quality of life thanks to the innovative devices it allows one to realize. New micro-processes and micro-technologies started to be developed and engineered, leading to constant increase of the volume of micro-devices manufactured as technological innovations become available to allow new productions.

In the current economic and environmental context, this trend cannot proceed without careful considerations about sustainability and environmental protection. Dealing with micro-scale might lead to the improper belief that the environmental impact of micro-manufacturing is lower than that of traditional manufacturing processes. Partly it could be so, thinking about the reduced use of raw materials, and thus a smaller production of waste, and the expected lower energy required. However, this common sense is not always valid, as proved by recent applications of Life Cycle Assessment to micro-manufacturing processes [1-3]. Different reasons can be identified as explanation.

In terms of factory layout and machinery technology, in the case of micro-manufacturing machines adapted from the concept of traditional manufacturing machines, processes are often bulkier than the parts they produce. This results in higher machine weight, transportation costs and floor occupation [4,5]. The micro-factory [6-9] emerged as a new promising concept of sustainable factory, with the additional advantage of adding flexibility due to the possibility of easy transportation to different manufacturing sites.

In terms of energy, the micro-scale of products and devices increases requirements for preventing pollution and guaranteeing the optimal thermal conditions in the working environment in order to preserve manufactured pieces and manufacturing instruments. Hence, the energy saving predicted in principle by the micro-devices fabrication is overcome by higher energy costs for ventilation, air conditioning and filtering systems for clean rooms [10].

Another source of energy inefficiency can reside in the Computer Numerical Controls (CNCs) that are embedded into micro-manufacturing machines. Though CNCs are responsible of the development of new manufacturing methods (for example technologies as laser machining, focused ion beam (FIB), electro-discharge machining (EDM), and LIGA, just to mention the most widespread), a drawback is evident for CNC-based micro-machines. Since these are currently derived from classical machine tools, they result in inefficiency because most of the energy is expended in moving the tables and to achieve high operation speed for the spindle to compensate for the small chip sizes $[11,12]$.

Finally, in terms of materials, micro-manufacturing processes might present considerable issues related to sustainability. Since they are mainly dedicated to the production of very high added value devices, for example in the biomedical or micro-electronics sectors, the materials required are often rare and of significant economic value (for example, gold, platinum, titanium, etc.). Consequently, 
waste derived from wrong or non-optimized process parameters can have a considerable impact in terms of raw materials costs and of new extraction processes. Furthermore, "intermediate parts" resulting from the need of an excess of material for manipulation or for guaranteeing the thermal stability of the process, can contribute to increase raw materials demand and costs. In micro-manufacturing, intermediate parts can represent up to $98 \%$ of components, as in the case of micro-injection molding [5]. Apart from raw materials, the need for higher purity levels in micro-manufacturing processes requires improved chemical purification through chemical substances and gases, with additional negative consequences in terms of environmental impact and costs.

These considerations indicate that the optimization of micro-manufacturing processes is a crucial task for guaranteeing a sustainable diffusion of these innovative technologies. Optimized processes, in fact, can favor the minimum consumption of precious raw materials, energy and critical chemicals. This results in a positive impact on their environmental and economic performances and, consequently, on the social benefits deriving from the higher diffusion among people of innovative devices that can improve quality of life.

Among micro-manufacturing, micro-EDM is frequently used to machine conductive materials regardless of their hardness and strength, accomplishing micro-sized features [13-17] and for fabricating micro-devices such as molds with/for micro-cavities and micro-channels, commonly found in micro fluidic components (i.e., lab-on-chip or micro cooling system) and in optical fiber connectors, as alignment systems. Micro-EDM machining is by far the most energy-intensive process and it may require a large resource consumption [3], considering that some high value-added materials such as $\mathrm{Si}$ wafer and gold are applied.

In addition, a specific issue arises with micro-EDM, where a dielectric fluid-usually a hydrocarbon-based fluid - is essential to increase the energy density during the electric discharge, thus improving the material removal process and debris removal from the working zone through a proper flushing. During micromachining, and in particular during the roughing regime, a considerable amount of micrometer-sized particles are removed and diffused in the dielectric, introducing the problem of adequate filtering and disposal of the contaminated substances.

In this paper, the analysis of the material removal mechanism of the micro-EDM milling process (concerning both the machined workpiece and the electrode tool) of micro-channels is performed in order to evaluate the quantity of debris, i.e., waste of the product, introduced in the dielectric fluid or, more generically, in the environment and identifying a technological solution to optimize the process to reduce this kind of material.

\section{Experimental Setup}

Micro-channels, having a length of $4.5 \mathrm{~mm}$, a width of $0.8 \mathrm{~mm}$ and a depth of $0.05 \mathrm{~mm}$, are machined on Ni-Cr-Mo steel using a Sarix SX 200 micro-EDM milling machine (Figure 1). The tool electrode is a Tungsten Carbide (WC) cylindrical rod, having a nominal diameter of $0.4 \mathrm{~mm}$ and negative polarity. The tool and the workpiece are constantly drizzled by a dielectric hydrocarbon oil, which guarantees the flushing during machining.

To proceed with the planned trials, the Design of Experiment (DoE) [18] is used to evaluate the influence of four electrical parameters, pulse width, frequency, discharge current and open voltage, on: 
- MRR, defined as the ratio between the material removed from the workpiece and the erosion time;

- TWR, defined as the ratio between volumes of material removed from the tool and the workpiece, respectively;

- And depth error, defined as the difference between theoretical and actual micro-channel depth.

Figure 1. The machined micro-channels.

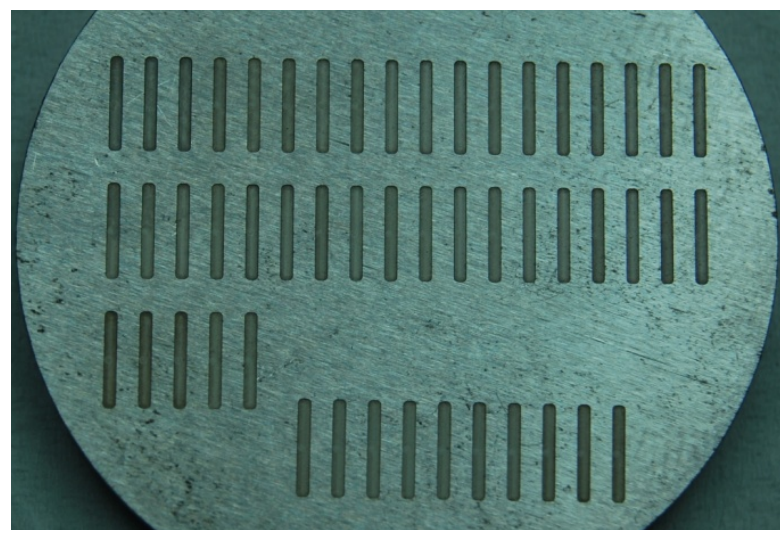

MRR is an index that qualifies how fast the process is and it is strictly related to the economy of the machining. TWR indicates how much electrode is worn in relation to the material removed from the workpiece. Both these indexes are useful to quantify how much debris can be released into dielectric oil and determine the pollution produced. It must be emphasized that the only way to reduce the debris, though preserving an accurate product, is to reduce the TWR. Finally, depth error can be considered as an index of the accuracy of the process.

Taking into account what the aforementioned indexes represent, the optimization of the technological parameters in terms of sustainability must be oriented to the minimization of the TWR, keeping MRR and depth error within acceptable level to guarantee the accuracy of the machining.

The design of experiment is based on a half fractional factorial method developed on two levels, ending up in 24-1 trials and a central point (indicated as Set of Parameters - SoP "0" in Table 1). Each test has been replicated 5 times, resulting in $40+1$ randomized experiments. The randomization has been applied both in execution sequence and space.

Table 1. Analyzed SoP and related electrical parameters.

\begin{tabular}{ccccccccc}
\hline SoP & $\begin{array}{c}\text { Width } \\
(\boldsymbol{\mu} \mathbf{s})\end{array}$ & $\begin{array}{c}\text { Frequency } \\
(\mathbf{k H z})\end{array}$ & $\begin{array}{c}\text { Current } \\
(\text { index })\end{array}$ & $\begin{array}{c}\text { Voltage } \\
(\mathbf{V})\end{array}$ & $\begin{array}{c}\text { Gain } \\
\text { (index) }\end{array}$ & $\begin{array}{c}\text { Gap } \\
\text { (index) }\end{array}$ & $\begin{array}{c}\text { Energy } \\
\text { (index) }\end{array}$ & $\begin{array}{c}\text { Regulation } \\
\text { (index) }\end{array}$ \\
\hline 0 & 2,5 & 160 & 120 & 120 & 200 & 79 & 100 & 4000 \\
1 & 1 & 120 & 100 & 100 & 200 & 79 & 100 & 4000 \\
2 & 4 & 120 & 100 & 140 & 200 & 79 & 100 & 4000 \\
3 & 1 & 200 & 100 & 140 & 200 & 79 & 100 & 4000 \\
4 & 4 & 200 & 100 & 100 & 200 & 79 & 100 & 4000 \\
5 & 1 & 120 & 140 & 140 & 200 & 79 & 100 & 4000 \\
6 & 4 & 120 & 140 & 100 & 200 & 79 & 100 & 4000 \\
7 & 1 & 200 & 140 & 100 & 200 & 79 & 100 & 4000 \\
8 & 4 & 200 & 140 & 140 & 200 & 79 & 100 & 4000 \\
\hline
\end{tabular}


It is worth noting that when micro EDM is employed to machine micro features, the electrode wear phenomenon, occurring during each and every micro EDM process and quantified by TWR index, can be carefully tackled. Electrode wear, in fact, is responsible of tool length variation which leads to a changing in the real milled channel depth within the workpiece, and on the planarity of the eroded layers, thus affecting the depth error. A wear compensation strategy is usually adopted [19-23] and implemented directly by program provided in the available micro-EDM machine. In particular, the uniform wear method (UWM) [19,20] is reckoned as the most suitable and widespread compensation method. The UWM operates according to a layer-by-layer machining strategy, assisted by constant electrode feeding in the Z-axis [21-23]. In other words, when a micro-feature is machined, the part program performing the machining can be set to check the wear of the electrode tool at fixed steps, for instance after a certain number of machined layers. At this program stage, the machining is temporarily suspended and the electrode is shifted to a control position (control point), where an electrical touch is made. If the comparison between the last value of tool length and the previous one is less than a fixed value (set within the part program), then the electrode is fed automatically and the machining is resumed at the same point where it has been interrupted. A parameter, called adjustment factor, affects the quantity of the electrode fed after the wear measurements. The adjustment factor is defined as the down-motion of the Z-axis per unit of displacement along XY tool path and is usually given as input parameter at the beginning of the machining. If the process is somehow unstable and too many short circuits occur during the process, the CNC supplies with automatic update of such a value in order to favor the stability of the machining. The electrode feeding is thus determined by the estimation of the wear ratio, performed by a wear prediction module and by the adjustment factor. In a previous work [24], we showed that the TWR and the adjustment factor (AF) are strictly connected and display the same trend in each considered milling process. However, it is worth stressing that UWM works at best when the hypothesis of negligible side erosion of the electrode is verified.

The tests have been performed using a layer by layer strategy: the layer thickness is set equal to 1 $\mu \mathrm{m}$ and the total depth of the channels is equal to $0.05 \mathrm{~mm}$. Other parameters, namely gain, gap, energy and regulation are kept constant in all experiments (Table 1), whereas the adjustment factors and the working diameters change for each SoP (Table 2). These latest parameters have been obtained by previous tests concerning the milling of square empty pockets and contours. These designs are used to optimize the adjustment factor value in a way which ensures the stability, accuracy and repeatability of $\mu \mathrm{EDM}$ process in dependence on the technological parameters chosen (SoP). The working diameter, which is defined as the sum of the electrode tool diameter and the sparking gap, completes the set of information, i.e., technological parameters, needed to perform more reliable trials on micro-channels.

In order to have reliable values to evaluate MRR, TWR and the actual depth of micro-channels, direct measurements have been performed in the following manner. At the end of each process, two different set of measurements have been done.

In order to quantify the electrode wear, some measurements are performed directly the control point, where the machine checks the electrode length: the spindle is driven to this point located on the workpiece, but sufficiently apart from the machined area. Two sets of electric touches are then performed: three with the tool and three without it (the electrode tool is retracted back inside the spindle). The difference between these data gives the remaining tool length. Since the initial electrode length is known, the length of tool wear can be easily calculated. TWR is consequently obtained as the 
ratio between eroded volume of the electrode tool and the volume of the material removed from the workpiece, available from the part program report files. The eroded volume is calculated by considering the area of the tool path in $x-y$ plane multiplied for the channel depth assessed by the machine (expected depth). MRR is then obtained by the ratio of this quantity and the erosion time provided by the machine reports.

Table 2. Adjustment factors and working diameters related to the analyzed SoP.

\begin{tabular}{ccc}
\hline SoP & Adjustment Factor & Working Diameter $(\mathbf{m m})$ \\
\hline 0 & 0.050 & 0.419 \\
1 & 0.046 & 0.423 \\
2 & 0.067 & 0.422 \\
3 & 0.060 & 0.425 \\
4 & 0.040 & 0.424 \\
5 & 0.060 & 0.428 \\
6 & 0.044 & 0.427 \\
7 & 0.044 & 0.427 \\
8 & 0.064 & 0.424 \\
\hline
\end{tabular}

The calculation of the actual depth of each micro-channel has been performed by executing:

- Three electric touches in correspondence of the control point (which is taken as a reference point);

- Three electric touches within the micro-channel.

These values are then averaged and the standard deviation is calculated in order to estimate the actual depth of each micro-channel. The depth error is then derived by the difference between the measured and expected depth values.

\section{Experimental Results and Discussion}

The data obtained at the end of each micro-channel machining are processed using Minitab ${ }^{\circledR}$ Software, a statistical software based on the analysis of variance (ANOVA) which allows to extract the desired details about the process. The post processing of the data are then displayed using some diagrams characteristic of the ANOVA method; here the main effects plots, the Pareto diagram and the interaction plots are reported. The main effects plots show the behavior of each quality index (TWR, MRR and depth error) vs each selected parameter. The lines connecting two corner points feature a certain slope, which provides some indication on the performance of the index as each single parameter is varied, and are commonly centered around a desired value. The Pareto diagram highlights the process weight of the main parameters in a bar chart, along with main interactions among couples or triplets of parameters. A red line typically sets the limit of importance of such parameters in terms of statistical relevance and significance. The ones lying at the right of this value are the most important parameters from a statistical point of view. The interaction plots summarize the inter-dependence of all parameters, considering couple of them as a third one is varied. The validity of the assumptions for ANOVA application was checked by the examination of residuals based on normal distribution and homoscedasticity evaluations. 
The inspection of main effects plots, Pareto diagram and interaction plots related to the estimation of MRR, reported in Figure 2, highlights a sophisticated dependence of MRR on electrical parameters.

Figure 2. Main effects plot (a), Pareto diagram (b) and interaction plots (c) for material removal rate (MRR).
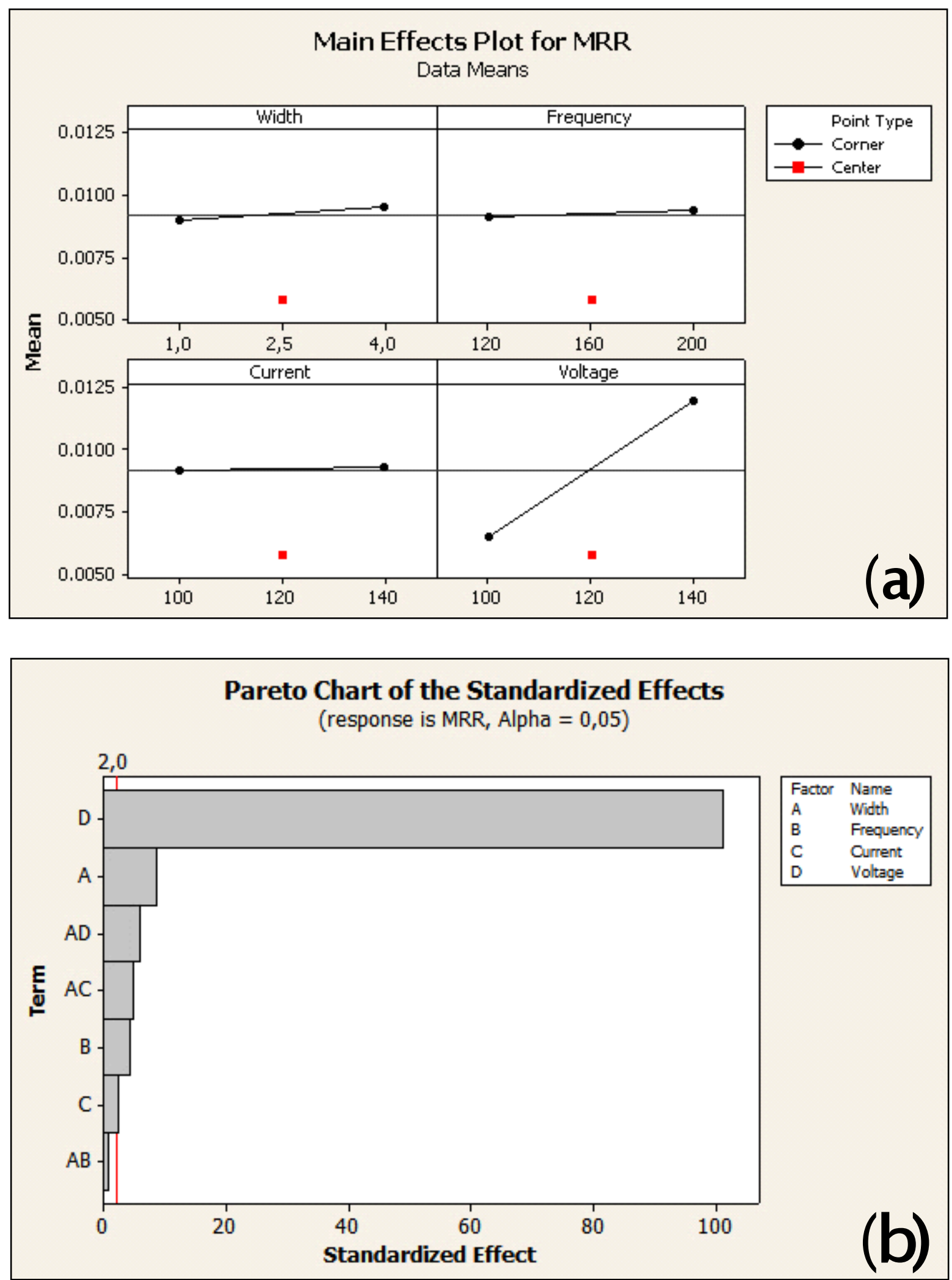
Figure 2. Cont.

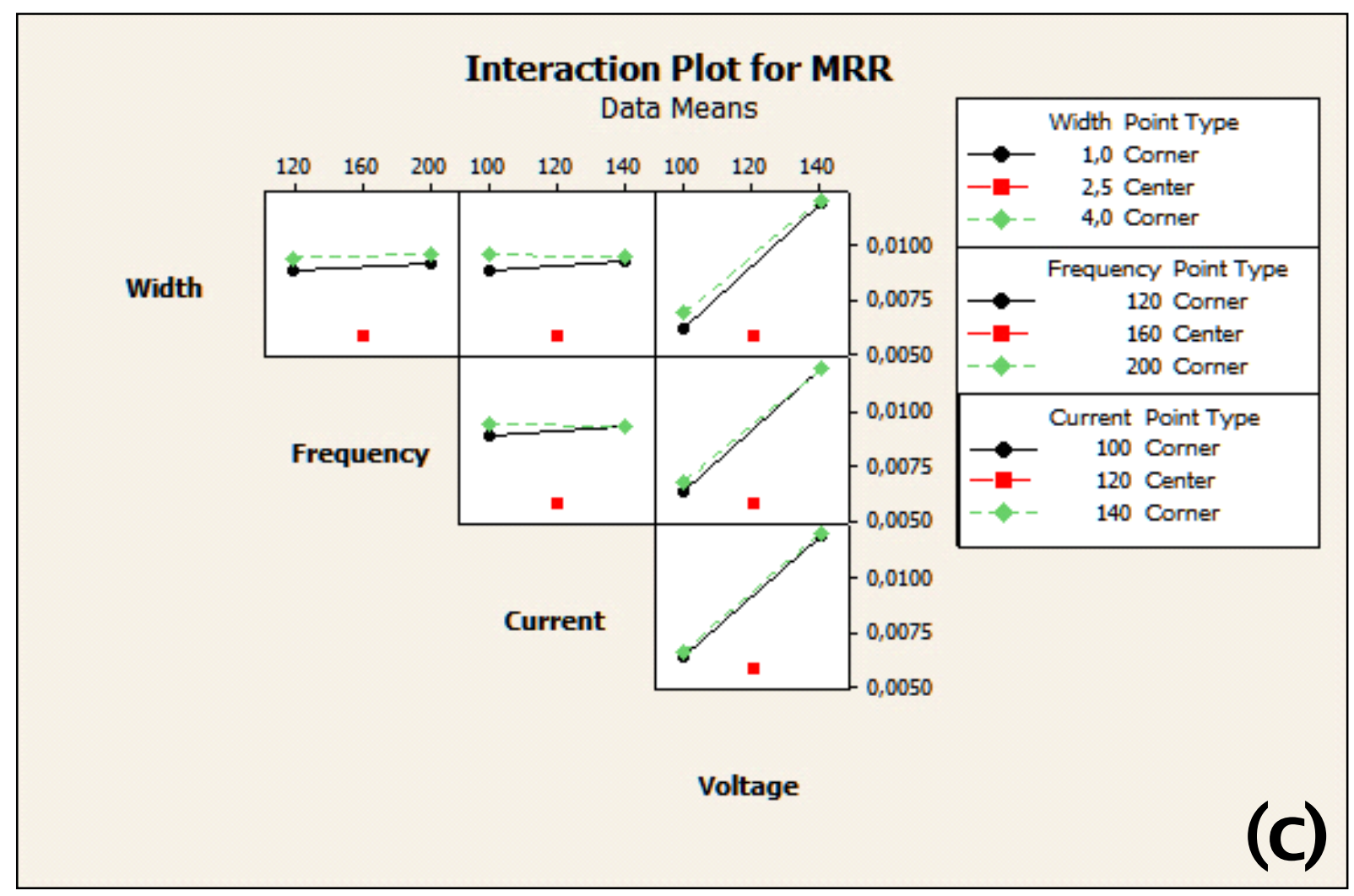

The main role can be ascribed to open voltage: from the inspection of Figure 2(a,c), MRR can be significantly increased by increasing this parameter. However, the Pareto diagram shows less evident though statistically relevant parameters intervening in the MRR: pulse width, combinations between width-voltage and width-current. Also, frequency and current compete in the material removal process. The interaction of width and current can be explained by the fact that they are linked to the discharge energy.

Main effects plot, Pareto diagram and interaction plot for TWR are reported in Figure 3.

In this case, Figure 3(a) shows that TWR is mainly affected by voltage and in a lighter way by width. The Pareto reported in Figure 3(b) confirms the dependence on voltage and reveals also that a combination voltage-width has a certain impact on tool wear process. The influence of width and interaction of width-current should be also taken into account. The interaction plot in Figure 3(c) shows other characteristics for the tool wear: a strong interaction between current-frequency and a light interaction current-width, voltage-width and voltage-frequency.

It is worth stressing that other interaction between frequency-current, frequency-voltage and current-voltage, which are not present in either the Pareto diagrams or interaction plots previously reported, cannot be resolved using the half factorial method.

In Figure 4 the Main Effects plot, Pareto diagram and the interaction plot related to the depth error are depicted. 
Figure 3. Main effects plot (a), Pareto diagram (b) and interaction plots (c) for tool wear ratio (TWR).
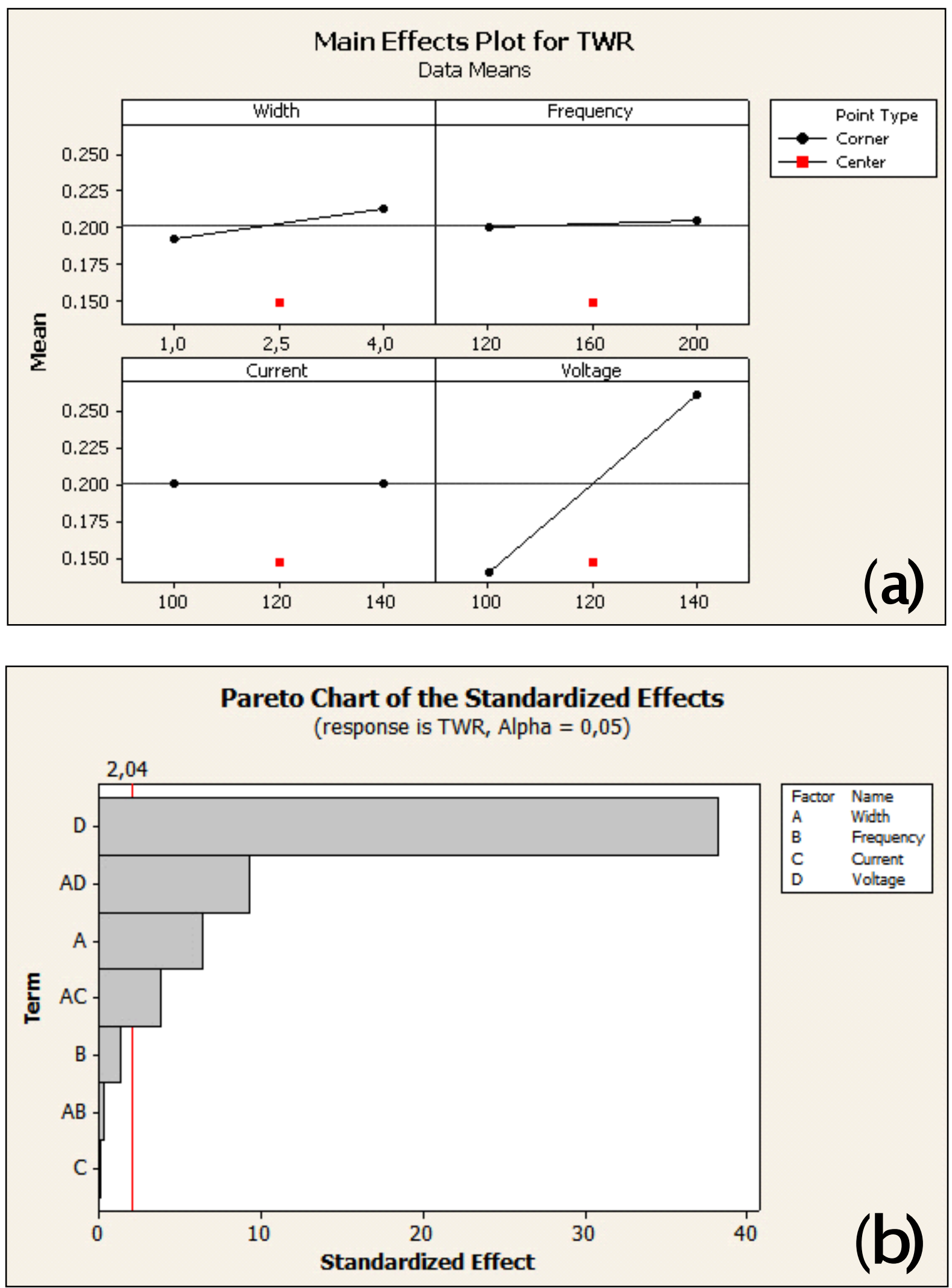
Figure 3. Cont.

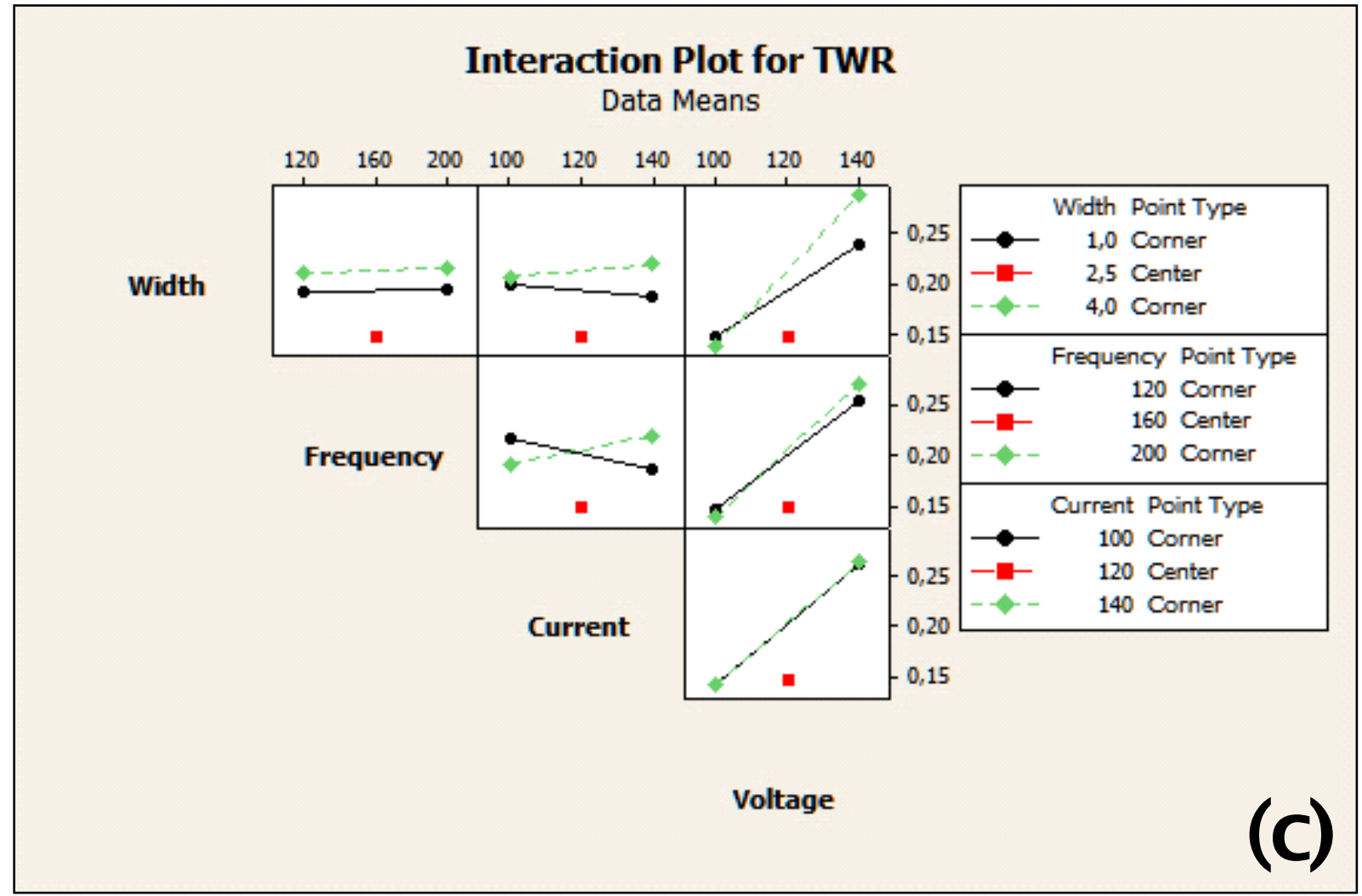

Figure 4. Main effects plot (a), Pareto diagram (b) and interaction plots (c) for depth error.

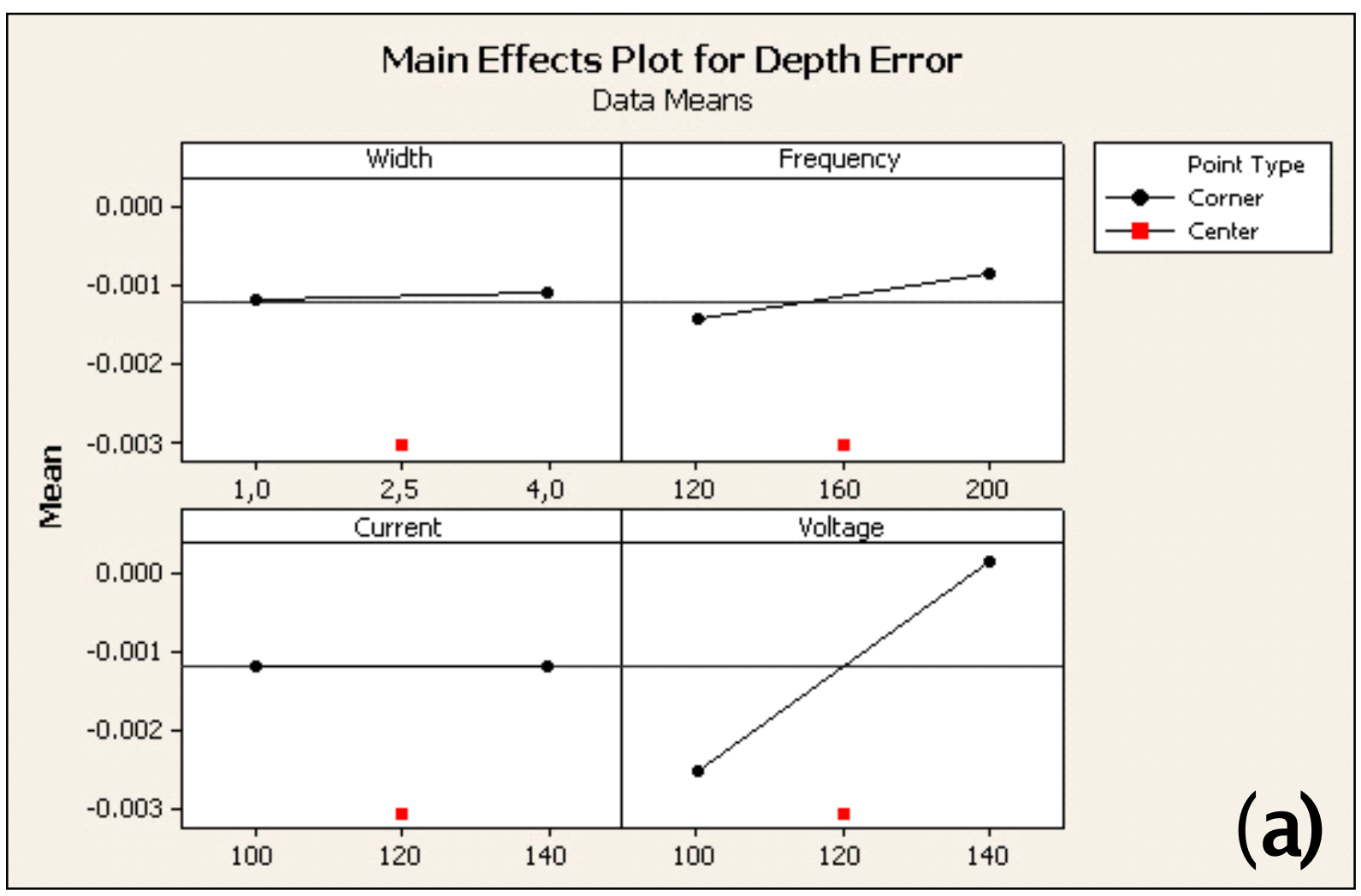


Figure 4. Cont.
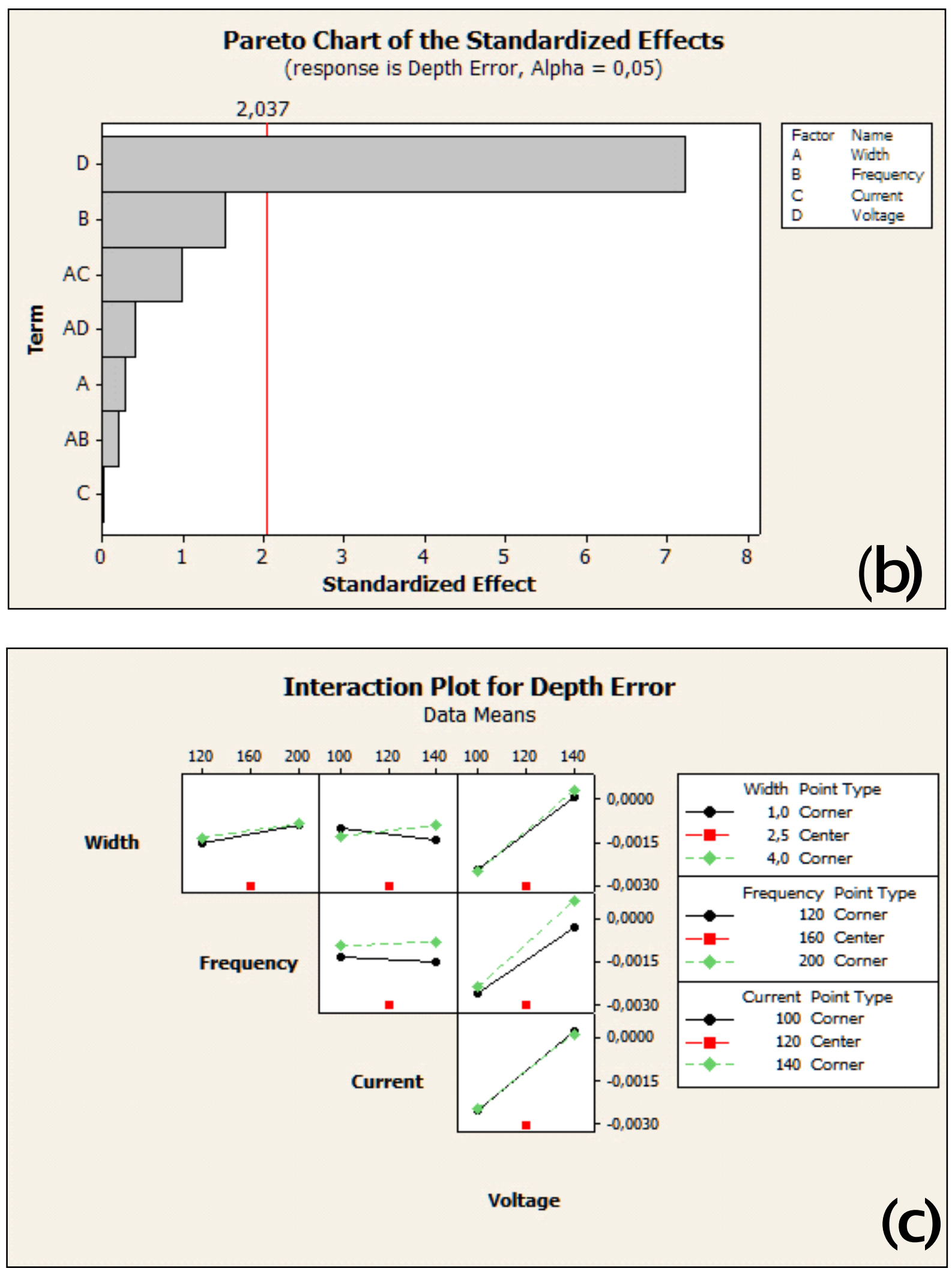

Also in this case, Figure 4(a,b) underline that the depth error is mainly and hugely affected by voltage, that is, in this analysis, the only significant parameter; in a very slight way, as one can infer from the interaction plots in Figure 4(c), frequency, the combination between current-frequency and current-width can be checked. 
The optimization of the technological parameters passes through the minimization of TWR, followed by the maximization of MRR and reduction of depth error, considering different values of weight and importance in the determination of the desirability function. The optimized technology can be then directly identified in the decrease of open voltage, though this choice could reasonably lead to a worsening of MRR and depth error. For this reason, this preliminary investigation will be followed by a more thorough one, eventually comprising a full factorial method, which allows us to highlight all hidden interactions among all parameters and select the optimize technology preserving reasonable MRR and depth error values.

\section{Conclusions}

Process optimization in micro-manufacturing is essential to guarantee the sustainable development of innovative micro-technologies. The use of high added-value raw materials and the need of a cleaner working space to preserve products' quality and machinery performance can in fact represent important sources of additional costs and negative environmental impacts. This is especially true in Micro-EDM machining, which is one of the most energy-intensive micro-process and which may require considerable consumption of rare materials.

Several experiments concerning micro-channels machined on hardened steel and a subsequent statistical analysis permitted us to obtain a first set of optimized parameters to finally realize the micromold in the respect of quality and with the minimum consumption of resources. The DOE, based on the half factorial approach developed on two levels with a central point, has been used to evaluate the MRR, TWR and depth error, as function of open voltage, discharge current, pulse width and frequency. Main effects plots, Pareto diagrams and interaction plots show that open voltage has the strongest impact on all quality indexes. By the minimization of TWR, and in a less important way, maximization of MRR and minimization of depth error, the optimized and "sustainable" SoP can be deduced: in particular, the TWR minimization requires the minimum value of voltage, though this requirement could eventually cause a decrease in MRR and increase in depth error. This SoP will be subjected to further investigation in order to find out a trade-off in minimizing TWR without significant variation on MRR and depth error.

\section{Acknowledgements}

This research has been supported by the project REMS ('Rete lombarda di eccellenza per la meccanica strumentale e laboratorio esteso'), funded by Lombardy Region under the framework 'Promozione accordi istituzionali'.

\section{Conflict of Interest}

The authors declare no conflict of interest. 


\section{References and Notes}

1. De Grave, A.; Olsen, S.I.; Challenging the sustainability of micro products development. In Proceedings of the 2nd International Conference on Multi-material Micro Manufacturing, (4M 2006), Grenoble, France, 20-22 September 2006; pp. 285-288.

2. De Grave, A.; Hansen, H.N.; Olsen, S.I. Sustainability of products based on micro and nano technologies. In Proceedings of the 4th International Symposium on Nanomanufacturing (ISNM 2006), Cambridge, MA, USA, 1-4 November 2006; pp. 40-45.

3. De Grave, A.; Olsen, S.I.; Hansen, H.N. Life Cycle Assessment of micro manufacturing process chains-Application to the microfactory concept, 2007. 4M Network of Excellence Web site. Available online: http://www.4m-net.org/files/papers/4M2007/367195/PID367195.pdf (accessed on 1 September 2011).

4. Nawata, S.; Aoyama, T. Life-cycle design system for machined parts-Linkage of LCI data to $\mathrm{CAD} / \mathrm{CAM}$ data. In Proceedings of the Second International Symposium on Environmentally Conscious Design and Inverse Manufacturing (EcoDesign'01), Tokyo, Japan, 12-15 December 2001; p. 299.

5. Qin, Y. Micro-Manufacturing Engineering and Technology; Elsevier: Amsterdam, The Netherlands, 2010; Chapter 25, pp. 394-404.

6. Okazaki, Y.; Mishima, N.; Ashida, K. Microfactory-concept, history and developments. J. Manuf. Sci. Eng. 2004, 126, 837-844.

7. Ban, Y.B.; Lee, K.; Oh, S. 5-axis micro-milling machine for machining micro parts. Int. J. Adv. Manuf. Technol. 2004, 25, 888-894.

8. Kussul, E.; Baldyk, T.; Ruiz-Huerta, L.; Caballero-Ruiz, A.; Velasco, G.; Kasatkina, L. Development of micromachine tool prototypes for microfactories. J. Micromech. Microeng. 2002, 12, 795-812.

9. Okazaki, Y. Microfactories-A new methodology for sustainable manufacturing. Int. J. Autom. Technol. 2010, 4, 82-87.

10. Plepys, A. The environmental impacts of electronics. Going beyond the walls of semiconductor fabs. In Proceedings of the IEEE International Symposium on Electronics and the Environment, Phoenix, AZ, USA, 19-23 May 2004.

11. Liow, J.L. Mechanical micromachining: A sustainable micro-device manufacturing approach? J. Clean. Prod. 2009, 17, 662-667.

12. Boothroyd, G.; Knight, W.A. Fundamentals of Machining and Machine Tools, 2nd ed.; Marcel Dekker, Inc.: New York, NY, USA, 1989.

13. Ho, K.H.; Newman, S.T. State of the art electrical discharge machining (EDM). Int. J. Mach. Tools Manuf. 2003, 43, 1287-1300.

14. Pham, D.T.; Dimov, S.S.; Bigot, S.; Ivanov, A.; Popov, K. Micro-EDM-recent developments and research issues. J. Mater. Process. Technol. 2004, 149, 50-57.

15. Lim, H.S.; Wong, Y.S.; Rahman, M.; Edwin Lee, M.K. A study on the machining of high-aspect ratio micro-structures using micro-EDM. J. Mater. Process. Technol. 2003, 140, 318-325. 
16. Liu, K.; Paris, J.; Ferraris, E.; Lauwers, B.; Reynaerts, D. Process investigation of precision micro-machining of $\mathrm{Si}_{3} \mathrm{~N}_{4}$-TiN ceramic composites by electrical discharge machining (EDM). In Proceedings of the 15th International Symposium on Electromachining (ISEM), Pittsburgh, PA, USA, 23-27 April 2007; pp. 221-226.

17. Liu, K.; Lauwers, B.; Reynaerts, D. Process capabilities of micro-EDM and its applications. Int. J. Adv. Manuf. Technol. 2009, 47, 11-19.

18. Montgomery, D.C. Design and Analysis of Experiments, 7th ed.; Wiley: New York, NY, USA, 2009.

19. Bissacco, G.; Tristo, G.; Valentinčič, J. Assessment of electrode wear measurement in micro-EDM milling. In Proceedings of the 7th International Conference on Multi-Material Micro Manufacture, Bourg en Bresse and Oyonnax, France, 17-19 November 2010; pp. 155-158.

20. Yu, Z.; Masazawa, T.; Fujino, M. Micro-EDM for three-dimensional cavities-Development of uniform wear method. Ann. CIRP 1998, 47, 169-172.

21. Bleys, P.; Kruth, J.P.; Lauwers, B.; Zryd, A.; Delpretti, R.; Tricarico, C. Real time tool wear compensation in milling EDM. Ann. CIRP 2002, 51, 157-160.

22. Yu, Z.; Masazawa, T.; Fujino, M. 3D micro-EDM with simple shape electrode. Int. J. Electr. Mach. 1998, 3, 7-12, 71-79.

23. Yu, Z.Y.; Kozac, J.; Rajurkar, K.P. Modelling and simulation of micro-EDM process. CIRP Ann. Manuf. Technol. 2003, 52, 143-146.

24. Modica, F.; Marrocco, V.; Trotta, G.; Fassi, I. Micro electro discharge milling of freeform micro-features with high aspect ratio, ASME 2011. In Proceedings of the International Design of Engineering Technical Conferences and Computers and Information in Engineering Conference, Washington, DC, USA, 28-31 August 2011; DETC2011-48331.

(C) 2011 by the authors; licensee MDPI, Basel, Switzerland. This article is an open access article distributed under the terms and conditions of the Creative Commons Attribution license (http://creativecommons.org/licenses/by/3.0/). 